\title{
A INSERÇÃO DO PROFESSOR NOS ANOS INICIAIS DO ENSINO FUNDAMENTAL: A CONSTRUÇÃO DE SUA IDENTIDADE PROFISSIONAL
}

\author{
Tânia Cristina Silva Pessoa, Raimunda Abou Gebran
}

Universidade do Oeste Paulista - UNOESTE, Programa de Mestrado em Educação, Presidente Prudente, SP. E-mail: ragebran@hotmail.com

\section{RESUMO}

Como em toda profissão, a formação de professores tem uma trajetória construída historicamente marcada por características que estarão presentes na construção da identidade profissional. O objetivo deste estudo foi analisar e identificar a construção da identidade docente a partir do olhar do professor iniciante na Rede Municipal de Ensino Fundamental I. A metodologia utilizada foi a pesquisa qualitativa do tipo descritivo-interpretativo. Para coleta de dados, foi realizado questionário e entrevista semiestruturada com 8(oito) docentes iniciantes da Rede Municipal de Rancharia SP. Os resultados preliminares indicaram que os principais problemas desses profissionais foram: as dificuldades no desenvolvimento dos conteúdos curriculares, gestão em sala de aula, correlação entre teoria e prática e escassez de experiência e apoio de Gestores e de Políticas Públicas. Conclui-se que é extremamente necessária a implantação de programas de apoio por parte do setor público para atender a inserção desses profissionais no ambiente escolar.

Palavras-chave: Professor Iniciante; Inserção Docente; Ciclo de Vida Docente; "Choque de Realidade"; Identidade Docente.

\section{THE INTEGRATION OF TEACHERS IN THE EARLY YEARS OF BASIC EDUCATION: THE CONSTRUCTION OF A PROFESSIONAL IDENTITY}

\begin{abstract}
As in any profession, teacher training has a built trajectory historically marked by features that will be present in the construction of professional identity. The aim of this study was to analyze and identify the construction of teacher identity from the view of the beginning teacher in the Municipal Schools in elementary school in Rancharia/SP. The methodology used was qualitative research of descriptive and interpretative. A questionnaire and a semi structured interview with eight (8) beginners teachers of the Municipal Schools in Rancharia/SP was conducted for data collect. The preliminary results Indicated that the main problems of these professionals were: Difficulties in the development of the course contents, class management, correlation between theory and practice and a lack of experience and support from Managers and from Public Policy. It is concluded that it is extremely necessary to introduce support programs from the public sector to attend the inclusion of these professionals in the school environment. Keywords: Beginner teacher; Insert Teacher; Teaching Life Cycle; " Reality shock "; Teacher identity.
\end{abstract}

\section{INTRODUÇÃO}

Com intuito de iniciarmos esta discussão sobre o momento de inserção na carreira docente, não podemos deixar de enfatizar a "figura" do professor iniciante e destacar as novidades, as surpresas e as dificuldades que este profissional encontra no início de sua carreira. Sobre isso, Lotumolo $(2014$, p. 23) comenta que "a docência é uma profissão que se caracteriza por expectativas, desejos, medos e angústias, seja em qual for a situação que o professor se encontre".

Papi (2014) relata que a formação docente está inserida primeiramente no âmbito de formação humana e das relações sociais, e que este processo se articula por meio da construção da vida em sociedade, sendo marcado por rupturas e contradições. Para a autora, é preciso considerar que o conceito de formação docente, possui uma dimensão pessoal que se 
relaciona ao desenvolvimento humano, o que desvincula ser restritamente à técnica.

Libâneo (2012, p.55) afirma que:

A prática profissional de professores não é uma mera atividade técnica, não se constitui como mero fazer resultante de habilidades técnicas, mas como atividade teórica e prática, uma atividade prática que é sempre teórica, pensada, e um movimento do pensamento, do que resulta uma prática pensada.

$O$ ato de formar é complexo, exige diversos elementos constitutivos da formação que se estabelecem nas relações humanas, epistemológicas, sociais, cognitivas, entre outras, assim a realidade educacional também é complexa, com grandes diferenças, históricas, políticas e sociais, e a relação entre a teoria e a prática pedagógica na formação de professores precisa estar atrelada a um processo de formação compatível com o contexto social, político e econômico (VEIGA, 2013).

Neste sentido, Ferreira (2014, p. 40) acrescenta:

Os conhecimentos
adquiridos nos cursos de
formação
(inicial/continuada) precisam
imprimir em seus discentes,
características de uma
formação que busque a
teorização acadêmica, a
criticidade, a reflexão sobre
a prática, a pesquisa como
possibilidade para novos
conhecimentos que a
docência enfrenta na
contemporaneidade.
(FERREIRA, 2014, p.40).

Ainda nesta perspectiva, Behrens (2006, p.143) enfatiza que a formação de professores na contemporaneidade precisa superar a fragmentação presente na formação e para isso requer um novo posicionamento, ou seja, um novo paradigma de formação. Para a autora, o professor ao posicionar-se nesse novo contexto de desenvolvimento da ação docente deve reconhecer que, complexidade não é apenas um ato intelectual, mas também o desenvolvimento de novas ações individuais e coletivas.

Corroborando a esse pensamento, Tescarolo $(2010$, p.2) afirma que a formação de professores precisa assumir a "concepção de conhecimento de mundo", com o intuito de dialogar e contextualizar sobre a realidade atual que a Educação está inserida.

Portanto, ser professor na atualidade demanda enfrentar desafios colocados à carreira docente, como as angústias quanto à realidade social, a falta de formação continuada, as questões referentes à remuneração, a busca quanto a valorização social, entre outros. Esses elementos precisam ser considerados pelos formadores de professores, principalmente na preparação da entrada destes profissionais na carreira docente, pois a atuação docente tem grande contribuição no processo de transformação social.

Mariano (2006) afirma que o início da profissão docente tem relação com a trajetória escolar de cada docente inserido no contexto de sua individualidade, isto pode subtender a ideia de que o futuro professor já saiba como desenvolver o trabalho dentro da escola e sala de aula, pois ele já passou pelos espaços escolares, anteriormente, como estudante. Porém, essas mudanças nos papéis, ou seja, de aluno para professor traz inesperadas situações nunca vividas e também muitas vezes pouco trabalhadas em sala de aula.

$O$ docente traz consigo a formação inicial, todavia, quando assume a sala de aula, muitas vezes se sente incapaz. O contexto em si traz ansiedade ao iniciante que pode interferir no desempenho de sua atividade e bloquear os conhecimentos anteriores. $O$ docente conhece o contexto em que está inserido, contudo, esse momento inicial pode fazer com que se perca, precisando do apoio da instituição e de gestores a fim de que os oriente neste momento de mudança de posição, ou seja, de estudante a professor (ROCHA, 2006).

Este período de entrada para a docência é marcado por situações inusitadas, pois o novato se depara com momentos que demanda ações urgentes em sua rotina de trabalho e com o objetivo de acertar, vai experimentando atitudes que muitas vezes, não tem o êxito esperado e dessa forma perpassa por sentimentos conflitantes que provam sua resistência na profissão. Também é um momento importante para aquisição de competências para a iniciação 
nas rotinas de trabalho que persistirão em sua trajetória profissional.

A respeito disto, Huberman (2013) relata na que trajetória profissional de professores, existem diferentes etapas que estão presentes na vida pessoal e profissional e cada uma delas pode acontecer em momentos distintos, influenciando a maneira como eles se veem, reconhecem o seu trabalho e delimitam sua identidade. Assim, a docência passa por etapas, durante as quais os professores têm necessidades formativas e que possuem conhecimentos e experiências diferentes.

Sobre a abordagem da carreira docente e seus ciclos, optou-se neste trabalho pela perspectiva de Huberman $(2013$, p.39) ao afirmar que "existem diversas maneiras de se estruturar o ciclo de vida profissional docente". O autor traça um quadro-síntese das tendências gerais possíveis de identificar no ciclo de vida dos professores, descrevendo-as em fases que compõem a carreira do professor.

A primeira delas é tratada como entrada na carreira, ou seja, o processo fundamental envolvido nesta fase é o da "exploração", no sentido de determinar exatamente os parâmetros de ensino e os comportamentos que devem ser adotados. O "início" da carreira é marcado pela luta entre dois aspectos: a sobrevivência (entusiasmo) e a descoberta propriamente dita do que é ser professor. Conforme a maior ou menor facilidade sentida no início, os caminhos tomam sentido positivo ou negativo.

A estabilidade demarca a segunda fase que resulta de uma escolha pessoal subjetiva do ensino como carreira e de um ato administrativo com o compromisso entre o indivíduo e a instituição, "um comprometimento definitivo, a tomada de responsabilidade, a consolidação de um repertório pedagógico de base" no seio da classe. Nesta fase, são frequentes os sentimentos de competência pedagógica, que criam a sensação de segurança, descontração, confiança e conforto. Os professores nesta fase vivem sentimentos de satisfação.

A seguir, vem a fase da diversificação ou questionamento que é o pôr-se em questão; um período de desequilíbrio, divergindo os sentimentos profissionais pelo positivo e negativo, podendo ser identificada por "sintomas" que podem ir de um ligeiro sentimento de rotina a uma "crise existencial". Crise esta que pode ser explicada pela monotonia da vida cotidiana em situação de aula ou pelo desencanto motivado pelo fracasso das experiências. $O$ autor relaciona que seria o momento de decisão sobre a permanência (ou não) na docência, influenciado tanto pelas condições de trabalho nas escolas, quanto pelo sucesso pessoal obtido na carreira profissional.

A quarta fase descrita por é a fase da serenidade. Esta seria caracterizada por uma maior capacidade de reflexão e de satisfação pessoal, por uma crescente sensação de serenidade e confiança, por um menor nível de ambição e menor vulnerabilidade à avaliação dos outros (diretores, colegas, alunos etc.).

A fase seguinte é a do conservantismo $e$ lamentações e caracteriza-se por maior rigidez e resistência mais firme às mudanças e inovações, por uma nostalgia do passado e por uma atitude de queixa sistemática, de caráter conservador e não construtivo acerca dos alunos, do ensino, da política educacional e dos colegas mais jovens, considerados menos comprometidos e sérios com as questões educacionais.

Finalmente, a fase do desinvestimento, marcada por uma libertação progressiva do investimento no trabalho; o professor nesta fase passaria a consagrar mais tempo a si próprio e aos interesses externos à escola, dedicando maior atenção a sua vida pessoal e social.

O autor afirma que essas fases podem acontecer em momentos diferentes e que tais sequências não serão vividas sempre pela mesma ordem; não se trata de um modelo linear, uma vez que o desenvolvimento em uma carreira é "um processo e não uma série de acontecimentos" (HUBERMAN, 2013, p.38).

Assim, os ciclos devem ser vistos como um caminhar pela carreira e não uma série sucessiva de eventos pontuais, ou seja, nenhum docente se tornará um bom profissional na carreira rapidamente, mas por meio de experiências diárias de práticas com a teoria, e não apenas por observação do outro, como é apresentado no estágio (FELIX 2015, p. 57).

É interessante ressaltar que estes ciclos citados por Huberman, mais especificamente o ciclo inicial, traz aos docentes recém-formados, uma realidade que não é cotidianamente comentada no convívio universitário, como por exemplo, a ambientação com os colegas de trabalho, a rotina do contexto escolar, sua apresentação à sala de aula, dentre outros. Nesse novo ambiente, ao relacionar a sua experiência como discente para com suas atribuições, agora 
de docente, pode causar um desequilíbrio emocional e, principalmente, profissional para esse novo professor.

Esse momento de apresentação do docente é comentado por Sacristán (1998) ao afirmar que o professor passa por um momento de transição, ou seja, da experiência passiva como aluno para ativa como professor, sem que seja the oferecido de forma plena o real significado educativo, social e epistemológico do conhecimento que desenvolve com seus alunos.

O fato é que, o ingresso na carreira docente aponta muitas dificuldades, pois o novo professor depara-se com maiores responsabilidades e com necessidades de desapegar-se de muitas imagens construídas quando fora aluno, esses impasses tornam-se complicados nos primeiros anos de carreira profissional, muitas vezes impedindo que ele venha desempenhar de uma maneira qualitativa suas competências.

Contudo, vale ressaltar que a formação acadêmica privilegia os saberes das matérias de ensino e os professores iniciantes, a partir de uma visão conteudista, acredita estarem prontos e que o domínio dos conteúdos é a chave para desenvolver seu trabalho docente. Porém, ao perceberem que as exigências são mais abrangentes, vivem o que Veenman (1984) e Tardif (2002) denominam como "choque de realidade", sendo que o professor iniciante se confronta com as teorias ministradas no ambiente da formação acadêmica, com a prática, ou seja, as dimensões representadas pelos diversos movimentos do espaço escolar.

Leone (2011) descreve que o "choque de realidade" acontece devido a um desajustamento dos professores já no exercício da função. Para a autora, ocorre um distanciamento entre o significado e o alcance do seu trabalho e com isso tendem a vivenciar sentimentos de desânimos, desencantos, surpresas e tensões ao realizarem o seu trabalho.

De acordo com os apontamentos apresentados, faz-se necessário pensar a formação do professor iniciante e a construção de sua identidade profissional, pois por mais que o professor tente camuflar e fixar uma identidade de docente neste momento de inserção deparase com "estranheza" o que denuncia frustrações, sabores e dissabores o que revela as múltiplas identificações que formam essa identidade, complexa e heterogênea. Diante das reflexões apresentadas, surge o seguinte questionamento:
Quais aspectos que poderiam contribuir para a construção da identidade docente, em especial na fase inicial da carreira?

Silva (1997, p.59) afirma que "será no seio da própria escola que o professor inexperiente encontrará o apoio necessário para continuar a sua formação através de um trabalho conjunto com um gestor escolar". Essa fase crítica de "choque" descrita anteriormente, ou seja, o enfretamento de questões que faz refletir sobre a teoria e a prática no efetivo exercício docente, se (re) significa a todo instante.

Dessa forma, a construção da identidade docente está interligada a práxis profissional considerando as mudanças que ocorrem e afetam as relações no processo de ensino e aprendizagem e de como o professor se vê num determinado momento histórico de sua carreira.

Pimenta (1999) define que "a identidade do professor" se baseia em três elementos da docência: o primeiro trata dos saberes das áreas específicas, o referencial teórico; o segundo trata dos saberes pedagógicos, de processo de ensino e, por último, trata dos saberes de experiência, da construção do seu jeito de ser professor.

Na visão de Santos (2012) é necessário acrescentar que a identidade do professor envolve características pessoais e profissionais e que elas se constroem a partir das relações sociais que englobam o indivíduo, a instituição educacional, a família e os que influenciam de alguma maneira à estruturação do conhecimento.

Sendo assim, o processo de construção e (re) construção da identidade do professor se dá de maneira contínua, a partir de reflexões das suas experiências pessoais e profissionais que elaboram seus próprios saberes e conhecimentos e que vão the direcionar para construção de uma autonomia intelectual e com isso construção de sua identidade (SANTOS, 2012).

A identidade docente, muitas vezes, é identificada pelo trabalho desenvolvido pelo professor, pela sua didática na exploração dos conteúdos, a fim de atingir os objetivos e pela forma como se comporta diante dos seus afazeres como docente.

Pimenta e Lima (2011, p.62) argumentam que:

A identidade do professor é construída ao longo de sua trajetória como profissional do magistério. No entanto, é no processo de sua formação 
que são consolidadas as opções e intenções da profissão que o curso se propõe a legitimar.

Diante da afirmação acima vale ressaltar que os saberes iniciais não bastam, e que o aprender é contínuo na vida do docente, bem como, a construção de sua identidade profissional não é um produto acabado, é um lugar de lutas e conflitos, é um espaço de construção de maneira de ser e de estar na profissão (NOVOA, 1995).

Em suma, além de ver sua própria imagem e do seu trabalho, a identidade do professor também é constituída socialmente na relação dialética com os papéis e as representações sociais precedentes e com o grupo de trabalho. Para Nóvoa (1995, p.16), a respeito da identidade profissional docente 0 autor descreve que ela "não é um dado adquirido, não é uma propriedade, não é um produto".

Assim, o presente estudo tem por objetivo analisar e identificar a construção da identidade docente a partir do olhar do professor iniciante, mais precisamente sobre sua inserção na carreira bem como, compreender os conflitos e dificuldades no processo de iniciação à docência na Rede Municipal de Ensino Fundamental I, da cidade de Rancharia/SP.

\section{METODOLOGIA E SUJEITO DA PESQUISA}

Para o desenvolvimento da pesquisa, optou-se por uma abordagem qualitativa de caráter descritivo-interpretativo. $\mathrm{Na}$ abordagem qualitativa, o pesquisador procura aprofundar-se na compreensão dos fenômenos que estuda ações dos indivíduos, grupos ou organizações em seu ambiente e contexto social - interpretandoos segundo a perspectiva dos participantes da situação enfocada, sem se preocupar com a representatividade numérica, generalizações estatísticas e relações lineares de causa e efeito. Assim, a interpretação e a consideração do pesquisador são os principais instrumentos de investigação (TERENCE; ESCRIVÃO FILHO, 2006).

Martins (1994, p.28) define que "a pesquisa descritiva tem como objetivo a descrição das características de determinada população ou fenômeno, bem como o estabelecimento de relações entre variáveis e Fatos". Segundo Denzin e Lincoln (2006) a pesquisa qualitativa envolve uma abordagem interpretativa do mundo, o que significa que seus pesquisadores estudam coisas em seus cenários naturais, tentando entender os fenômenos em termos dos significados que as pessoas a eles conferem.

Quanto aos instrumentos de coleta, a pesquisa utilizou-se de uma "revisão bibliográfica", que para Lakatos e Marconi (2006) trata-se de uma revisão da literatura sobre os principais trabalhos já realizados, revestidos de importância, por serem capazes de fornecer dados atuais e relevantes relacionados com o tema escolhido. O segundo instrumento foi a "aplicação de questionário", para Gil (2009, p.128), pode ser útil quando um investigador pretende recolher informações sobre um tema e através da aplicação é constituído o público alvo. Quanto as questões, foram compostas de forma fechada e de múltipla escolha, para o autor, são perguntas nas quais o pesquisador apenas seleciona a opção, dentre as apresentadas, que mais se adéqua à sua opinião e tendo como vantagens, a rapidez, a maior uniformidade, a simplificação nas análises das respostas e a facilidade para categorizá-la, permitindo assim, uma melhor contextualização da questão.

O objetivo da aplicação do questionário foi delinear o perfil dos participantes, bem como compreender a trajetória e o percurso de formação e da vida profissional de cada um dos entrevistados. O questionário foi aplicado individualmente, com dia e horários agendados previamente tendo uma duração média de (20) vinte minutos. É necessário destacar que mesmo sendo um instrumento que não propicie diálogo, o fato da pesquisadora estar presente, pareceu ser uma estratégia adequada, tendo em vista que, permitiu esclarecer dúvidas de interpretação em relação a algum item apresentado.

Num terceiro momento recorreu-se ao procedimento de "entrevista semiestruturada", a fim de conciliar as vantagens que o questionário apresenta com a tentativa de superação de algumas de suas limitações. Mazzotti e Gewandsznajder (1999) afirmam que, a entrevista permite a abordagem de temas complexos, os quais, dificilmente, poderiam ser investigados e explorados, de maneira adequada e aprofundada, através do questionário. A opção pela entrevista semiestruturada, se justifica pela possibilidade que oferece ao pesquisador, em investigar significados subjetivos e esclarecer qualquer tipo de resposta, permitindo ao entrevistado certa liberdade ao narrar suas 
experiências, ainda que haja algum controle do pesquisador sobre a conversação (MOREIRA; CALLEFE, 2008; SZYMANSKI, 2008).

A entrevista objetivou levantar informações e questionamentos quanto à escolha da profissão, a percepção no acolhimento da escola, suas dificuldades, a construção de sua identidade docente, o ambiente escolar, a troca de saberes entre pares, o suporte pedagógico oferecido nas instituições, a avaliação do desempenho destes profissionais e as dificuldades encontradas nas práxis pedagógicas e outros aspectos sugeridos.

Por essa razão, embora o roteiro estivesse pré-elaborado, buscou-se utilizá-lo com alguma flexibilidade, lançando mão, quando necessário, de outras questões mais focadas no assunto, como por exemplo, as de aprofundamento e/ou de esclarecimento no transcorrer das entrevistas.

Quanto aos participantes da pesquisa, o estudo foi realizado em cinco escolas da Rede Municipal de Ensino Fundamental I do município de Rancharia/SP, com um total de 08 (oito) participantes, sendo eles, professores iniciantes na docência e que se enquadravam no critério estabelecido, conforme orientação de Huberman (2013), onde para o autor são considerados professores iniciantes, aqueles profissionais que possuem até 3 (três) anos de experiências na docência.

\section{RESULTADOS}

Quanto ao perfil dos participantes da pesquisa, dos oito docentes componentes da amostra, $100 \%$ foram do sexo feminino. Analisando a faixa etária delas, verificou-se que $25 \%$ estão entre 20 a 25 anos, $25 \%$ estão entre 26 a 30 anos, $37,5 \%$ estão entre 31 a 40 anos e apenas $12,5 \%$ estão acima de 40 anos de idade.

No tocante à formação, verificou-se que todas concluíram o curso de Pedagogia, sendo que $25 \%$ foi entre os anos de 2011 e 2012, 37,5\% entre os anos de 2013 e 2014 e $37,5 \%$ no ano de 2015, em relação a Instituição de Ensino
Superior, $100 \%$ das participantes cursaram em instituições de ensino privado.

Quanto à formação continuada e cursos de especialização ou pós-graduação, $37,5 \%$ delas não estão cursando nenhuma especialização ou pós-graduação na área de Educação e $62,5 \%$ estão cursando uma pós-graduação ou especialização na área de Educação.

Sobre o momento de inserção à carreira docente, foi levada em consideração uma análise temporal dos últimos cinco anos, tendo como resultado que nenhuma das profissionais entrevistadas ingressaram entre os anos de 2010 a 2012 na carreira, 25\% das participantes entre os anos de 2013 e 2014 e $75 \%$ delas no ano de 2015.

No que se refere à atuação docente dessas professoras, verificou-se que no ano de $2016,75 \%$ delas lecionam para alunos de $1^{\circ}$ ao $3^{\circ}$ ano do Ensino Fundamental e $25 \%$ para alunos matriculados no $4^{\circ}$ e $5^{\circ}$ ano do Ensino Fundamental.

Em se tratando das experiências anteriores dessas profissionais, observou-se que $75 \%$ possuíam experiências em sala de aula em média de 4 (quatro) meses, 12,5\% possuíam mais que um ano de experiência e somente uma entrevistada, possuí mais de dois anos de experiência no Ensino Fundamental.

Sobre a escolha da profissão docente, $62,5 \%$ escolheram em virtude da existência de uma faculdade instalada na cidade e por ter, segundo elas, um maior campo de trabalho dentro do município e $37,5 \%$ disseram que tinham desejos e sonhos de se tornarem professoras. Ao serem questionadas sobre sua inserção na carreira docente e se houve um choque de realidade no momento de sua entrada, $100 \%$ das docentes responderam que ao concluírem a graduação não se sentiram preparadas para começar a exercer a docência e dessa forma tiveram sim, um choque com a realidade, apresentando algumas dificuldades e desafios, conforme demonstrado no gráfico 1 : 


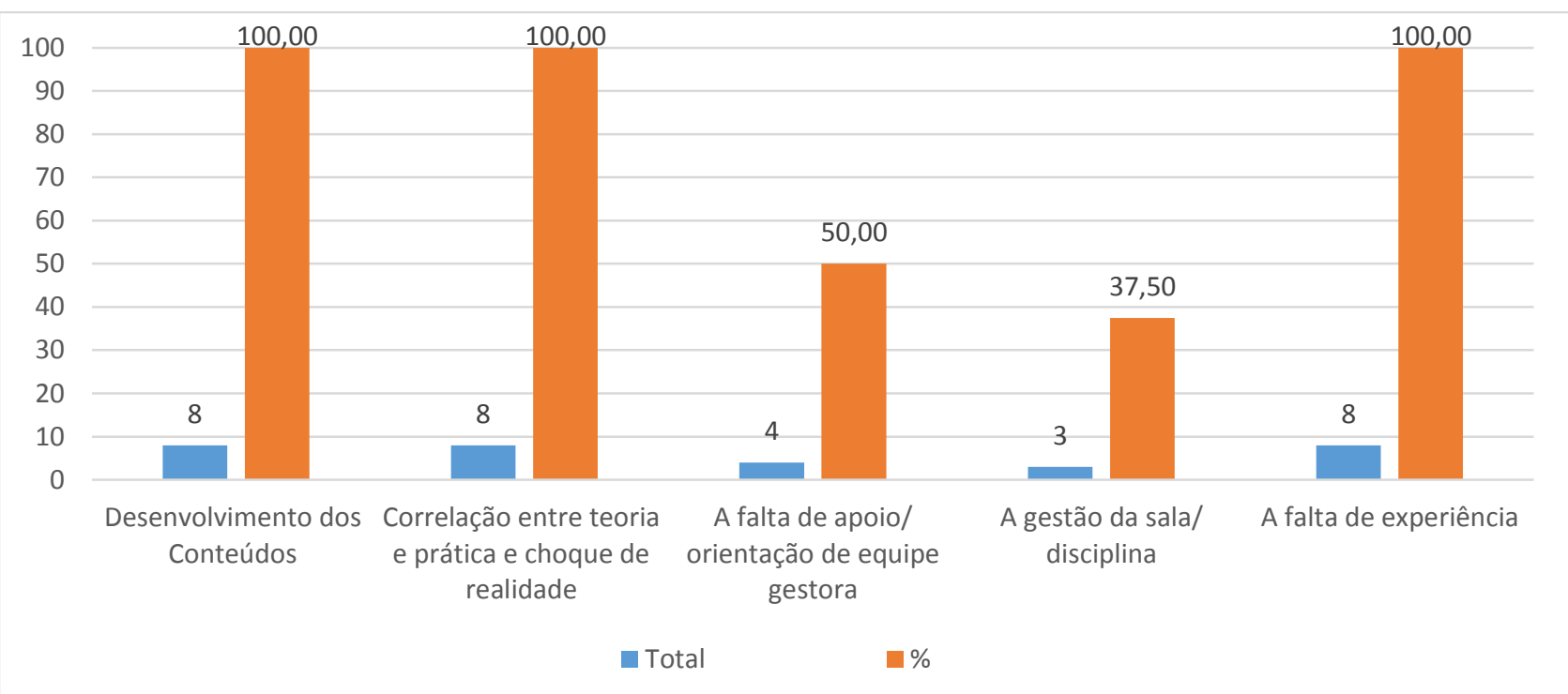

Gráfico 1. Dificuldades e Desafios encontrados na Pesquisa- início da docência

Fonte: autor (2016).

Ainda de acordo com os dados levantados acima, $100 \%$ das entrevistadas disseram que possuem dificuldades no desenvolvimento de conteúdo, o choque com a teoria adquirida na academia versus prática e a falta de experiência na sala de aula, 50\% delas indicaram a escassez de apoio por parte da equipe gestora e orientação pedagógica e 37,5\% das entrevistadas, apontaram ter dificuldade na gestão em sala de aula relacionada à disciplina.

Os questionamentos voltados sobre, "como gostariam de serem vistas como profissionais docentes no futuro, em média de 10 a 15 anos" e "como seria a construção de sua identidade docente", $100 \%$ das entrevistadas disseram que gostariam de ser reconhecidas profissionalmente pela sua competência e que para isso, há a necessidade de continuar buscando novos conhecimentos a serem agregados em sala de aula.

Por fim, ao serem questionadas sobre suas perspectivas futuras na carreira docente, $100 \%$ disseram que desejam continuar na carreira em virtude de razões subjetivas, como gostar de exercer a profissão docente.

\section{DISCUSSÃO}

É observado na pesquisa, que $100 \%$ dos sujeitos são do sexo feminino, indicando a feminização na docência no Ensino Fundamental. A proporção elevada de mulheres pode ser explicada pelo fato de considerar-se para fins de investigação, apenas o corpo docente dos anos iniciais do Ensino Fundamental, que neste caso há um número elevado de professoras quando comparados a outros níveis de ensino.

LEONI (2011, p. 153), afirma que o alto índice de professoras na docência dos anos iniciais revela uma dimensão do processo de feminização na docência que transcende a questão numérica em direção à reflexão acerca de suas implicações na construção das representações sociais sobre a profissão docente e na consolidação do estatuto profissional da docência.

Todas as participantes envolvidas na pesquisa são graduadas em instituições de Ensino Superior particulares, conforme comentado nos parágrafos anteriores. Foi constatado então, que o principal motivo de cursarem o ensino superior nesse modelo de instituição, é que existe no município e local da pesquisa, Instituições de cunho privado o que facilitou o seu ingresso na graduação em virtude das parcerias firmadas entre empresas e instituições somando-se a isso, nos últimos anos houve também a abertura de bolsas de estudo gratuitas oferecidas pelas esferas municipais, estaduais e federais, como por exemplo: Programa Escola da Família, Prouni - Programa Universidade para Todos, SISUSistema de Seleção Unificada e FIES- Fundo de Financiamento Estudantil que pelos quais, tiveram uma grande contribuição na formação desses indivíduos.

Com relação a formação continuada, $37,5 \%$ delas não deram continuidade na sua formação, justificando como principal motivo a falta de condições financeiras. 
Partindo do resultado apresentado sobre o número de professoras que assumiram a sala de aula no ano de 2016, atribuíram ao fato da vacância deixada por professores que foram convidados pela gestão municipal a ocuparem cargos comissionados na rede de ensino, como gestores, supervisores e outros.

O fato da pesquisa apresentar $100 \%$ de concordância das participantes em relação a dificuldade de sua inserção na carreira docente, as mesmas disseram que, não se sentiram preparadas ao assumirem uma sala de aula, devido à pouca experiência adquirida principalmente nos estágios supervisionados e pela carência de disciplinas na formação inicial que pudessem discutir os modelos de gestão educacional comumente usados na prática.

Todas as participantes da pesquisa, afirmaram que, se veem num futuro próximo, obtendo seu reconhecimento profissional de forma positiva. Segundo elas, isto é importante, e para que isto aconteça é necessário preparar-se no dia a dia, construindo uma rotina de trabalho coerente com o conteúdo que deve ser desenvolvido, a fim de que aluno aprenda. Do ponto de vista dessas professoras a identidade docente é construída ao longo de sua trajetória profissional e principalmente pelas experiências adquiridas.

Por fim, todas afirmaram que gostam de ser professora, e que não desejam mudar de profissão, por razões de identificação e principalmente pela afinidade com crianças.

\section{CONCLUSÃO}

A pesquisa teve como objetivo analisar e identificar a construção da identidade docente a partir do olhar do professor iniciante na Rede Municipal de Ensino Fundamental da cidade de Rancharia - São Paulo. A fundamentação teórica foi orientada principalmente pelos estudos de Huberman (2013), Veenman (1984), Nóvoa (2013) e Basso (1998).

Os principais problemas que afligem os docentes no momento da sua inserção na carreira docente são as dificuldades no desenvolvimento dos conteúdos curriculares, gestão em sala de aula, correlação entre teoria e prática e a escassez de apoio e experiência docente. Estes resultados encontrados nesta pesquisa corroboram com os achados dos estudos de Huberman (2013), onde afirmam que estes professores estão na fase da descoberta e/ou sobrevivência, para o autor os primeiros anos de docência são difíceis, conflituosos, ou seja, é um momento de adaptação e conquistas pessoais e profissionais.

$\mathrm{Na}$ pesquisa, $100 \%$ delas disseram ter vivido de fato o choque de realidade, ou seja, tiveram sentimento de medo, angústia, sensação de incapacidade e a falta de preparação profissional o que foi ao encontro dos estudos de Veenman (1984) onde descrevem que, estes profissionais estão passando por um processo de transição de idealismo, marcando a sua passagem definitiva de estudante para professor.

No levantamento, quanto a construção da identidade profissional docente, (um dos braços importante da pesquisa) foi identificado que as professoras relacionam esta construção a partir da imagem que elas têm de si e sobre o seu trabalho, mas também por identidades delegadas por meio de outros, ou seja, pelos professores, gestores, alunos, pais, enfim, pela comunidade onde convive e principalmente o reconhecimento de sua competência no ofício. Neste sentido, Nóvoa (2013, p.16) descreve que a identidade profissional não é um produto acabado, ela "é um lugar de lutas e conflitos, é, portanto, um espaço de construção de maneira de ser e de estar na profissão".

Todas as professoras, conforme apresentado na pesquisa, deixaram claro o seu desejo de prosseguirem na carreira, e seus argumentos apresentados revelam-se por razões de natureza implícita na docência, como por exemplo o gostar da profissão, o gostar de ensinar e o sentimento de realização profissional, mas também a de natureza explícita, que para elas tratam-se da responsabilidade de ensinar, o desenvolvimento do indivíduo e a formação do cidadão o que corrobora com os estudos de Basso (1998), ao afirmar que o significado social do trabalho do professor é constituído pela finalidade de ensinar, ou seja, pelo seu objetivo e conteúdo concreto, efetivados conscientemente pelo docente, tendo em consideração as condições reais e objetivas para a apropriação do conhecimento pelo aluno.

Os achados da pesquisa apontam que há necessidade de investimentos na área pedagógica. Os profissionais da área de Educação precisam não só de cursos de capacitação e palestras oferecidos pelas secretarias de educação dos municípios, mas também á necessidade de buscar novos investimentos pessoais, como por exemplo, a iniciação em pósgraduação, colaborando assim, com a sua 
formação e aprimoramento no desenvolvimento do ensino aprendizagem. Para minorar o "choque com a realidade" e alcançar a "Construção de sua Identidade como Docente" o cenário ideal seria a implantação de programas de apoio com monitoramento por parte do setor público, com a finalidade de atender esses profissionais no momento de sua inserção no ambiente escolar, atendendo metas do Plano Municipal de Educação.

\section{REFERÊNCIAS}

BASSO, Itacy Salgado. Significado e sentido do trabalho docente. Caderno Cedes, v. 19, no 44, 1998. Campinas.p.19-32. Disponível em:<http://www.virtual.ufc.br/solar/aula_link/lle sp/A_a_H/didatica_I/aula_01/imagens/03/signifi cado_sentido_trabalho_docente.pdf $>$.Acesso em: 15 abr.2016.

BEHRENS, Maria Aparecida. Paradigma da complexidade: metodologia de projetos, contraltos didáticos e portfólios. Petrópolis: Vozes, 2006.

DENZIN, Norman K. e LINCOLN, Yvonna S. Introdução: a disciplina e a prática da pesquisa qualitativa. In: (Orgs.). $O$ planejamento da pesquisa qualitativa: teorias e abordagens. 2. ed. Porto Alegre: Artmed, 2006. p. 15-41. FERREIRA, Jacques de Lima. A complexa relação entre teoria e prática pedagógica na formação de professores: formação de professores. Petrópolis: Vozes, 2014.

FELIX, Carla Fernanda Figueiredo. Identidade profissional docente: tecendo histórias. 2015. 223f. Dissertação (Mestrado em Educação) Faculdade de Educação da Universidade Estadual de Campinas. Disponível

em:<http://www.bibliotecadigital.unicamp.br/do cument/?view $=000956454>$. Acesso em: $20 \mathrm{abr}$. 2016.

GIL, Antônio Carlos. Métodos e técnicas de pesquisa social. 5. ed. São Paulo: Atlas, 2009. Disponível em:<http://www.uece.br/nucleodelinguasitaperi /dmdocuments/gil metodos de pesquisa.pdf> Acesso em 20 Jun. 2016.

HUBERMAN, Michael. O ciclo de vida profissional dos professores. In: NÖVOA, António (org.). Vidas de professores. 2. ed. Porto: Porto Ed., 2013. p. 31-61.

LAKATOS, Eva Maria; MARCONI, Marina de Andrade. Fundamentos de metodologia científica. 5. ed. São Paulo: Atlas 2006.
LEONE, Naiara Mendonça. Necessidades formativas dos professores dos anos iniciais na sua inserção no exercício da docência. 2011. Dissertação (Educação). Faculdade de Ciências e Tecnologia da Universidade Estadual Paulista, Campus de Presidente Prudente - SP.Disponível em:<http://repositorio.unesp.br/bitstream/handl e/11449/90200/leone_nm_me_prud.pdf?sequen ce=1\&isAllowed=y>Acesso em: 10 Abr. 2016.

LIBÂNEO, José Carlos. Temas de pedagogia: diálogos entre didática e currículo. São Paulo: Cortez, 2012. p. 33-60.

LOTUMOLO, Thais Elena. Professores Iniciantes: como compreendem o seu trabalho? São Carlos: UFSCAR, 2014. 108 f. Dissertação (Mestrado em Educação). Disponível em:<https://repositorio.ufscar.br/bitstream/han dle/ufscar/2697/5778. pdf?sequence=1\&isAllowe $\mathrm{d}=\mathrm{y}>$ Acesso em: 10 Abr.2016.

MARTINS, Gilberto de Andrade. Manual para elaboração de monografias: trabalhos acadêmicos, projetos de pesquisa, relatórios de pesquisa, dissertações, 50 resumos de dissertações. São Paulo: Atlas, 1994. MAZZOTTI, Alda Judith Alves; GEWANDSZNAJDER, Fernando. $\mathbf{O}$ método nas ciências naturais e sociais: pesquisa quantitativa e qualitativa. 2. ed. São Paulo: Pioneira Thomson Learning, 1999. $203 \mathrm{p}$.

MOREIRA, Herivelto; CALEFFE, Luiz Gonzaga.

Metodologia da pesquisa para o professor pesquisador. 2. ed. Rio de Janeiro: Lamparina, 2008. 245p.

MARIANO, André Luiz Sena. A construção do início da docência: um olhar a partir das produções da ANPEd e do ENDIPE. 2006. $156 \mathrm{f}$. Dissertação (Mestrado em Educação) - Centro de Educação e Ciências Humanas, Universidade Federal de São Carlos, São Carlos, 2006.

Disponível em:<https://repositorio.ufscar.br/bitstream/han dle/ufscar/2796/DissALSM.pdf?sequence=1\&isAll owed=y >Acesso em: 15 abr.2016.

MONTEIRO, Hilda Maria. Eu não sabia o que agora sei...: tornando públicas as minhas histórias secretas. In: LIMA, Emília Freitas de (Org.).

Sobrevivências no início da docência. Brasília: Líber Livro, 2006. p. 27-38.

NÓVOA, Antônio. O passado e o presente dos professores. In: (Org.). Profissão professor. 3. ed. Porto: Porto, 1995. p. 13-34. NÓVOA, Antônio. Os professores e as histórias da sua vida. In: NÖVOA, António (Org.). Vidas de professores. 2. ed. Porto: Porto Ed., 2013. 
PAPI, Silmara de Oliveira Gomes. Professoras iniciantes: formação, experiência e desenvolvimento profissional. Pro-Posições, v. 25, n. 1, p. 199-218, 2014. Disponível em:<http://www.scielo.br/pdf/pp/v25n1/v25n1a 11.pdf>. Acesso em: 20 abr. 2016. PIMENTA, Selma Garrido (Org.). Saberes pedagógicos e atividade docente. São Paulo: Cortez, 1999.

PIMENTA, Selma Garrido; LIMA, Maria Socorro. Estágio e docência. São Paulo: Cortez, 2011. ROCHA, Gisele Antunes. Por uma política institucional comprometida com o início da carreira docente enquanto um projeto coletivo. In: REUNIÃO ANUAL DA ANPED, 29., 2006, Caxambu. Trabalhos... São Carlos: [s.n.], 2006. Disponível em: < http://www.anped.org.br/sites/default/files/gt08 -2611-int.pdf >. Acesso em: 10 abr.2016 SACRISTÁN, José Gimeno. 0 currículo uma reflexão sobre a prática. Porto Alegre: Artmed, 1998.

SANTOS, Maria de Cássia dos. A construção de identidade profissional docente: relatos de Histórias de Vida. 2012. Dissertação (Ciência da Educação) - Universidade Lusófona de Humanidades e Tecnologias, Lisboa. Disponível em:

<http://recil.grupolusofona.pt/handle/10437/280 1. >Acesso em 10 abr. 2016. SILVA, Maria Celeste Marques da. Viver e construir a profissão docente. Porto: Porto Ed., 1997. p. 51-80. (Coleção Ciências da Educação, n. 26).

SZYMANSKI, Heloisa. Entrevista reflexiva: um olhar psicológico sobre a entrevista em pesquisa. In: SZYMANSKI, Heloisa (Org.); ALMEIDA, Laurinda Ramalho de; PRANDINI, Regina Célia Almeida Rego. A entrevista na pesquisa em Educação: a prática reflexiva. 2. ed. Brasília: Liber Livro, 2008. p. 9-61. (Série Pesquisa, v. 4). TARDIF, Maurice. Saberes docentes e formação profissional. 2. ed. Petrópolis: Vozes, 2002. TERENCE, Ana Claudia Fernandes.; ESCRIVÃO FILHO, Edmundo. Abordagem quantitativa, qualitativa e a utilização da pesquisa-ação nos estudos organizacionais. In: ENCONTRO NACIONAL DE ENGENHARIA DE PRODUÇÃO, 26. 2006, Fortaleza/CE. Anais... [S.I.]: Enegep, 2006. Disponível em:<http://www.abepro.org.br/biblioteca/enege p2006_tr540368_8017.pdf>.Acesso em: 10 Jun. 2016.
TESCAROLO, Ricardo. A formação de professores no contexto da metamorfose civilizatória contemporânea. Curitiba: PUCPR. 2010. VEIGA, IIma Passos Alencastro. A aventura de formar professores. Educar em Revista. 2013.<Disponível em:<http://www.scielo.br/scielo.php?script=sci arttext\&pid=S0104-40602013000400020 >. Acesso em: 15 mai. 2016.

VEENMAN, Simon. Perceived Problems of Beginning Teachers. Review of Educacional Research, v. 54, n. 2, p. 143-178, 1984.

Recebido para publicação em 27/07/2016 Revisado em 05/08/2016

Aceito em 15/08/2016 